\title{
Prehistoric and Primitive Surgery
}

THE Vicary lecture before the Royal College of 1 Surgeons was delivered on December 8 by Dr. L. W. G. Malcolm, conservator of the Wellcome Historical Medical Museum, who chose as his subject "Prehistoric and Primitive Surgery".

The surgery of prehistoric and primitive times cannot be treated on rational lines when it is considered in time and space. There is all the difference in the world between the ideas of primitive man and those of the founders of rational medicine and surgery-the Greeks. It does not appear that there is any community of ideas in the primitive world unless considered from the ritualistic point of view.

Omitting for the most part reference to prehistoric Europe, to which detailed attention, especially in regard to trephining, has been paid by Dr. Wilson Parry, the available evidence shows that certain major operations have been performed by the prehistoric and primitive surgeons, involving a greater or less degree of skill and knowledge of anatomy; but such methods of treatment as bandaging, poulticing, lancing, bone-setting and the rarer amputation, massage, especially in relation to child-birth, cupping and bleeding, blistering and cauterising, fomentation and the vapour-bath were more or less common knowledge of the tribe, as the product of a real, if perhaps uncritical, experience.

The leechcraft of the professional medicine-man, or shaman, is in a different category. Although he has a knowledge of everything the lay medicineman may practice, he is able to control the basis of magic, the universal power or soul-mana. Magical therapeutics may be traced from the earliest times down to the present day. The magical ritual had an accompanying expression in some therapeutic measure, for example, bloodletting or massage. When a medicine-man, for example, trephined a head, he was performing a rite to satisfy the religious beliefs of the tribe; but as the tribe progressed in knowledge, the ritual process was abandoned and an allegorical object substituted as an offering to the god. Thus a gourd with a hole in it was offered to the god, who accepted it as a trephined head in lieu of the actual operation.

Turning to the rational surgery of primitive and prehistoric peoples, trephining of the skull was practised by the pre-Columbian inbabitants of Peru, the methods employed falling into four groups : scraping, sawing, cutting, and drilling, the last being rare. The objects of the operation were to treat a depressed fracture, such as might be caused by a sling-shot, to relieve pain or for superstitious reasons. The evidence on the whole does not support the use of a plate to fill the hole, or of suture. The operation is reported to-day, especially in North Africa, Polynesia, India and Peru.
The lesion now known as the sincipital $\mathrm{T}$ is found on skulls from the dolmens near Nantes in France. It takes the form of a long antero-posterior groove along the sagittal suture, terminating near the obelion where the transverse branch is encountered. It has been recorded among the ancient Canary Islanders as due to the cauterising of a scarification with a flint knife, and a similar lesion has been found in a pre-Columbian female skull from Peru. In the Middle Ages this operation was performed on demented individuals, usually female, to allow the application of heated objects to the skull. It reduced "the amount of cold humours in the head".

The disease uta, a phase of leishmaniasis, has left traces on certain skulls from South America. The primitive surgeon would appear to have amputated the diseased part of the face in one example. The effects of this treatment are represented in the realistic Peruvian prehistoric pottery.

In major surgical operations, the most astounding is the Cæsarian operation performed by a native of Uganda in 1879. The wound healed entirely on the eleventh day. A similar operation has been recorded among the Chippeway Indians, but without detail. Ovariotomy is said to be performed in India and among the aborigines of Australia ; but exact evidence is lacking. Although the Aztecs and Incas must have acquired a knowledge of anatomy from the practice of extracting the heart from the living sacrificial victim, they do not seem to have been led thereby to perform operations on the internal organs.

Hernia was treated among the Pueblo Indians of America by the use of pads and bandages, and the Basket-makers used a flattish oval pad. This was worn by new-born infants by means of long strings to prevent umbilical hernia. Umbilical hernia is extremely common among primitive peoples, especially in Africa; but they do not appear to do anything for it.

From the prehistoric pottery it would appear that the Incas performed some remarkable operations on the limbs. The cliff-dwellers of North America, who suffered severely from fractures, were skilled in the use of splints for thigh and arm, a purpose for which the Aztecs used the leaves of the century plant, moist clay serving as a cast. The aborigines of South Australia coat the fractured limb in a kind of plaster of Paris. Among the North American Indians, manipulation and particularly traction, manual and mechanical, were employed in the reduction of dislocations. Relaxation was produced by the use of stramonium, alcohol, infusions of tobacco and other drinks.

Three methods of blood-letting are practised by primitive peoples: suction, scarification and venesection. Ingenious methods of venesection were employed. One found among the Indians of 
the Isthmus and Brazil was to shoot a stoneheaded arrow into the vessel. This method is also found in New Guinea. Venesection is employed in the armpit, the forehead, the vertex and various other parts of the body. In Peru the veins at the root of the nose were opened. The use of the cupping vessel is widespread.

The stopping of a blood-vessel presents diffi. culties; but the methods employed are amazing in their variety, including powdered gum, charcoal, ashes, eagle's down, bandages of bark, coconut fibre, etc. A kind of tourniquet of bark cloth is recorded in Loyalty Islands, Tahiti, Samoa and Tonga. The prevalent method of cleansing wounds among the American Indians was by sucking out the pus, a method which gave the shaman opportunity to display his magic power by showing a pebble which he had sucked from the wound.

While it has been shown from the examples quoted above that the primitive peoples of America had a certain idea of rational surgical procedure, the remainder of the primitive world, with few exceptions, did not exhibit the same degree of surgical appreciation. The races and tribes of Africa who practise an advanced procedure have derived their knowledge from other races-all tribes south of the Sahara, for example, have been influenced by Arabian surgery. There is, however, a remarkable number of mutilations which involve a certain knowledge of surgery. These are usually ritualistic in origin, such as circumcision (male and female) and infibulation. There are no less than fourteen different methods of operating on the male genitalia employed in various parts of the primitive world. Among other forms of mutilation is amputation of the fingers, which was practised by the Aurignacian peoples of palæolithic times and is recorded by imprints on rocks in California, Arizona, Peru, Africa and Australia. Cicatrisation is also a sacrament. Other mutilations in a variety of forms are practised on the nose and cheeks. Piercing the tongue is not common, but excision of the tongue is practised in West Africa.

A review of the subject leads to the belief that the resistance of primitive people is abnormal, compared with that of modern civilised races. Their apparent indifference to pain and the infrequency of blood-poisoning indicate that modern races pay for their civilisation in terms of lessened resistance, pathology and neurology.

The lecturer expressed his acknowledgments to Dr. R. Moodie and Dr. L. Freeman.

\section{Artificial Production of a New Kind of Radio-Element}

\section{By F. Joliot and I. Curie, Institut du Radium, Paris}

COME months ago we discovered that certain $D$ light elements emit positrons under the action of $\alpha$-particles ${ }^{1}$. Our latest experiments hare shown a very striking fact: when an aluminium foil is irradiated on a polonium preparation, the emission of positrons does not cease immediately, when the active preparation is removed. The foil remains radioactive and the emission of radiation decays exponentially as for an ordinary radioelement. We observed the same phenomenon with boron and magnesium ${ }^{2}$. The half life period of the activity is $14 \mathrm{~min}$. for boron, $2 \mathrm{~min}$. $30 \mathrm{sec}$. for magnesium, $3 \mathrm{~min}$. $15 \mathrm{sec}$. for aluminium.

We have observed no similar effect with hydrogen, lithium, beryllium, carbon, nitrogen, oxygen, fluorine, sodium, silicon, or phosphorus. Perhaps in some cases the life period is too short for easy observation.

The transmutation of beryllium, magnesium, and aluminium $\alpha$-particles has given birth to new radio-elements emitting positrons. These radioelements may be regarded as a known nucleus formed in a particular state of excitation; but it is much more probable that they are unknown isotopes which are always unstable.

For example, we propose for boron the following nuclear reaction :

$$
{ }_{5} \mathrm{~B}^{10}+{ }_{2} \mathrm{He}^{4}={ }_{7} \mathrm{~N}^{13}+{ }_{0} n^{1}
$$

${ }_{7} \mathrm{~N}^{13}$ being the radioactive nucleus that disintegrates with emission of positrons, giving a stable nucleus ${ }_{8} \mathrm{C}^{13}$. In the case of aluminium and magnesium, the radioactive nuclei would be ${ }_{15} \mathrm{P}^{30}$ and ${ }_{14} \mathrm{Si}^{27}$ respectively.

The positrons of aluminium seem to form a continuous spectrum similar to the $\beta$-ray spectrum. The maximum energy is about $3 \times 10^{6} \mathrm{e.v}$. As in the case of the continuous spectrum of $\beta$-rays, it will be perhaps necessary to admit the simultaneous emission of a neutrino (or of an antineutrino of Louis de Broglie) in order to satisfy the principle of the conservation of energy and of the conservation of the spin in the transmutation.

The transmutations that give birth to the new radio-elements are produced in the proportion of $10^{-7}$ or $10^{-6}$ of the number of $\alpha$-particles, as for other transmutations. With a strong polonium preparation of 100 millicuries, one gets only about 100,000 atoms of the radioactive elements. Yet it is possible to determine their chemical properties, detecting their radiation with a counter or an ionisation chamber. Of course, the chemical reactions must be completed in a few minutes, before the activity has disappeared.

We have irradiated the compound boron nitride (BN). By heating boron nitride with caustic soda, gaseous ammonia is produced. The activity separates from the boron and is carried away with the ammonia. This agrees very well with the hypothesis that the radioactive nucleus is in this case an isotope of nitrogen.

When irradiated aluminium is dissolved in 